\title{
Diagnosis of Peritoneum Tuberculosis during a Herniotomy
}

\author{
I. Oualili, K. Khattala, F. B. Balde, A. Boutahar, A. Mahmoudi, Y. Bouabdellah \\ Department of Pediatric Surgery, University Hospital Center Hassan II, Fez, Morocco \\ Email: oualili.imane@gmail.com
}

How to cite this paper: Oualili, I., Khattala, K., Balde, F.B., Boutahar, A., Mahmoudi, A. and Bouabdellah, Y. (2020) Diagnosis of Peritoneum Tuberculosis during a Herniotomy. Open Journal of Pediatrics, 10, 661-665. https://doi.org/10.4236/ojped.2020.104068

Received: September 28, 2020

Accepted: December 1, 2020

Published: December 4, 2020

Copyright (อ 2020 by author(s) and Scientific Research Publishing Inc. This work is licensed under the Creative Commons Attribution International License (CC BY 4.0).

http://creativecommons.org/licenses/by/4.0/ (c) (i) Open Access

\begin{abstract}
Background: Tuberculosis is still a public health problem in the third world. The peritoneal localization is common even in pediatric patients. The macroscopics aspects of the peritoneal and/or intestine granulations are pathognomonic. However, its diagnosis by an inguinal hernia is exceptional. Our work aims to discuss the particularities of this unusual presentation of peritoneal tuberculosis. Case report: A 10-year-old girl who presented with a painless inguinal hernia. In per operatory, there was a granulomatous inflammation of the vaginalis process. The diagnosis of tuberculosis was confirmed by histopathologic study and the patient started the anti-tuberculosis drugs. After one year of follow-up, the girl is good and has no symptoms. Discussion: Opinions are divided when to cure the hernia. Is it necessary to do a laparoscopic exploration and biopsy then to secondarily cure the hernia; or go through the inguinal way to cure the hernia and do a peritoneal biopsy? In our case, we performed by the same surgical time the cure of the hernia and the biopsy and it did not impact negatively the follow-up. Conclusion: This revelation mode of peritoneal tuberculosis by inguinal hernia is exceptional but possible.
\end{abstract}

\section{Keywords}

Inguinal, Hernia, Tuberculosis

\section{Introduction}

Tuberculosis is still a public health problem in the third world. Its incidence in Morocco is 88 cases per 100,000 [1]. The peritoneal localization is common even in pediatric patients. We perform in our formation a peritoneal biopsy by laparoscopy for its diagnosis. The macroscopics aspects of the peritoneal and/or intestine granulations are pathognomonic. However, its diagnosis by an inguinal 
hernia is exceptional. Anyway, this localization does not change the management of the peritoneal tuberculosis.

Our work aims to discuss the particularities of this unusual presentation of peritoneal tuberculosis.

\section{Case Report}

A 10-year-old girl presented with a 2-month history of left inguinal swelling that was irreducible and associated with abdominal distention, followed by fever at $39^{\circ} \mathrm{C}$.

There was no pulmonary tuberculosis history and not know with any disease.

On admission her vital signs were stable, she was thin and there was no lymphadenopathy or skin mucosal pallor.

The abdominal examination revealed an irreducible left inguinal hernia associated with abdominal distention. There was no abdominal pain nether and organomegaly and the Flot sign was positive.

Biological parameters: Hemoglobin of $13 \mathrm{~g} / \mathrm{dl}$, TLC 8600 c/mm, ESR: 40 min 1 hour (Westergren method).

Chest X-Ray was normal.

Abdominal ultrasound described a massive ascites and a left inguinal hernia.

A diagnosis of incisional hernia in the left groin was made and he was taken up for anatomical repair of the hernial defect.

Intraoperative exploration found an inflamed and hardened hernial sac [Figure 1].

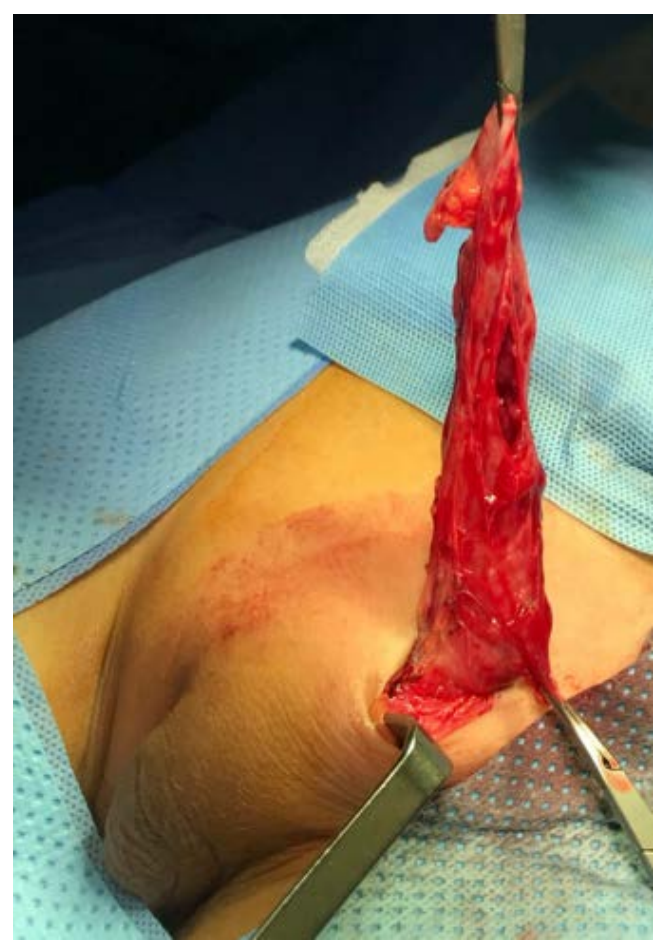

Figure 1. Inflamed hernial sac. 
When the sac was opened, the content was citrus yellow serous ascitic fluid with multiple granulations on the peritoneal surface [Figure 2].

The sac was ligated and sectioned. The sac has been sent for histopathology study.

The patient was put on anti-tuberculosis treatment given the operative aspect of the peritoneum and the epidemiological context.

This diagnosis was secondarily confirmed by histological analysis, in which, the redundant sac showed surface necrosis with multiple epithelioid granuloma with Langhan's type of giant cells [Figure 3].

After one year of follow-up the girl is good and has no symptoms.

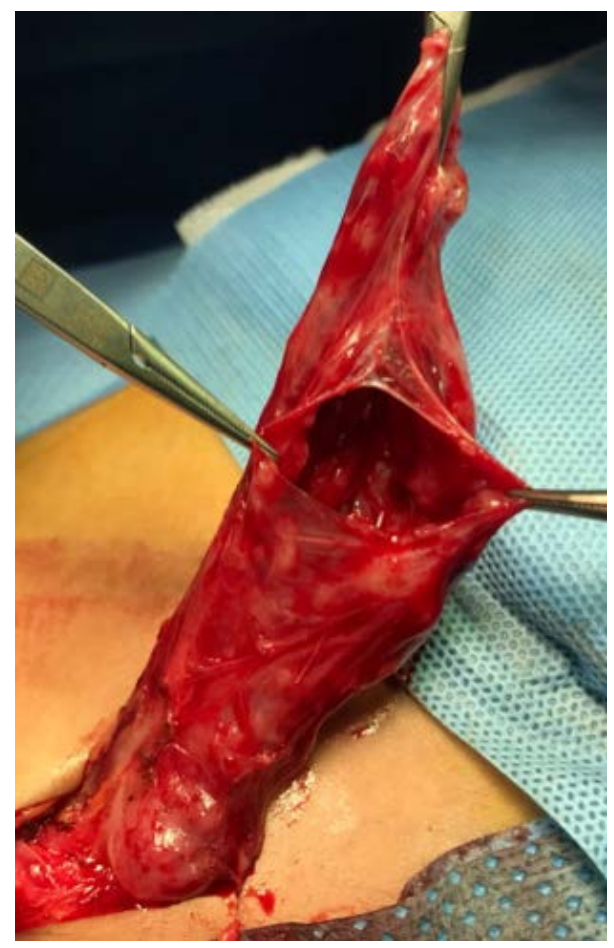

Figure 2. Multiple granulations inside the sac.

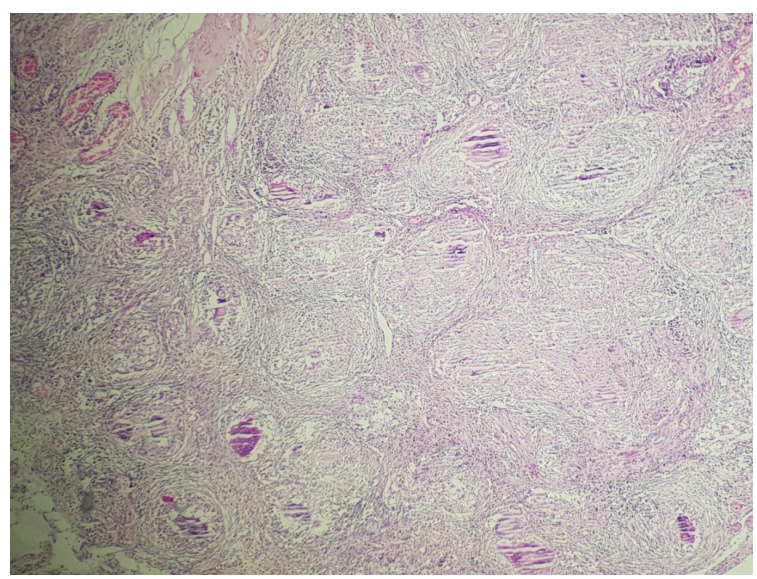

Figure 3. Several contiguous granulomatous formations separated by fibrous septa. Giant cells. 


\section{Discussion}

Peritoneal tuberculosis is a common presentation of extra-pulmonary tuberculosis in children. It usually presents as ascites, abdominal pain, anorexia and weight loss [2] [3].

A congenital inguinal hernia is the manifestation of patent processus vaginalis (continuation of peritoneum in the inguinal canal) [4].

For the pediatric surgeon finding an abdominal structure in the inguinal canal during a herniotomy is common. The tuberculosis affects primarily the peritoneum, and it can affect the hernial sac.

This case illustrates an unusual clinical presentation of abdominal tuberculosis as an inguinal hernia.

We did our research on PubMed and Google Scholar using the keywords: inguinal, hernia, tuberculosis. The results led to 3 cases of diagnosis of peritoneal tuberculosis at the hernial level in children, all were boys [5] [6] [7]. Our case is the first one to a girl.

Our patient was 10 years old; which joins the epidemiological data of peritoneal tuberculosis in children in our context [2].

Peritoneal tuberculosis is primitive. Our patient had no history of pulmonary or extrapulmonary tuberculosis; we assume that the hematogenous way or the direct ingestion of the bacillus would be the contamination way; which is also reported in the literature [8].

She was tin, had ascites and a large simple left inguinal hernia. These first 2 signs are common in the peritoneal tuberculosis presentation.

The presence of tubercules granulations into the hernial sac, can have several implications. Inflammatory adhesions of the sac caused the irreducibility of the herniawithout being complicated.

Actually, laparoscopy has been of great help in the diagnostic process of peritoneal tuberculosis. It consists of a laparotomy to look for peritoneal granulations and possibly doing a biopsy for histopathological confirmation [2] [4].

In front of this patient with a large inguinal hernia with a suspicion of peritoneal tuberculosis; is it necessary to do a laparoscopic exploration and possibly biopsy then to program her secondarily for cure of its hernia which is troublesome? Or go through the inguinal way to cure the hernia and do a peritoneal biopsy?

In the literature opinions are divided.

Some author recommends a subsequent cure for the hernia after anti bacillary treatment, because a herniorrhaphy on peritoneal inflammation would increase the risk of recurrence of the hernia [9]. However, these are studies on an adult population and we know that the principle of treatment of hernia is different in children.

Seen to the age, the hernial volume and the possibility of having a peritoneal biopsy by inguinal way; we opted for a hernia cure and by the same way explore and do the peritoneal biopsy.

To ensure prompt healing of the local tissues and avoid the formation of fis- 
tula, anti-tuberculosis drug should be immediately initiated for local healing [4] [9].

\section{Conclusion}

This revelation mode of peritoneal tuberculosis by inguinal hernia is exceptional but possible. Performing by the same surgical time the cure of the hernia and the biopsy has no negative impact in the follow-up.

\section{Ethics}

The parent's consent is obtained to use the patient's data for publication. We strictly respect confidentiality and there is no way to identify the patient by the images.

All the authors have contributed from the conception of the article to the final correction and approved the manuscript content.

\section{Conflicts of Interest}

The authors declare no conflicts of interest regarding the publication of this paper.

\section{References}

[1] Direction de l'Épidémiologie et de Lutte contre les Maladies "Manuel de référence du système d'information sanitaire du programme national de lutte antituberculeuse" Ministère de santé ; Maroc 2016.

[2] Bazine, M. and El Madi, A. (2016) L'intérêt de laparoscopie dans le diagnostic de la Tuberculose péritonéale chez l'enfant; Thèse. Université sidi mohammed ben abdellah faculté de medicine et de pharmacie; Fès Maroc $\mathrm{N}^{\circ}$ : 079/16. http://scolarite.fmp-usmba.ac.ma/cdim/mediatheque/e theses/79-16.pdf

[3] Blanc, P., Perrin, I., Barlet, L., Talbotec, C., Goulet, O., Paupe, A., Lenclen, R. and Carbajal, R. (2004) Peritoneal Tuberculosis in Children: Report of Two Cases. Archives de pédiatrie, 11, 822-825. https://doi.org/10.1016/j.arcped.2004.03.124

[4] Knowles, C.H. (2013) The Peritoneum, Omentum, Mesentery and Retroperitoneal Space. In: Williams, N.S., Bulstrode, J.K.C. and O'Connell, P.R., Eds., Bailey \& Love's Short Practice of Surgery, 26th Edition, Great Britain. CRC Press, Taylor \& Francis Group, 976.

[5] Lazarus, J. and Pillay, K. (2011) Abdominal Tuberculosis Presenting as an Inguinal Hernia in a Child.

[6] Dhandore, P., et al. (2016) Unusual Finding in the Inguinal Canal: Abdominal Tuberculosis Presenting as Inguinal Hernia. Journal of Clinical and Diagnostic Research, 10, PD13-PD14. https://doi.org/10.7860/JCDR/2016/16643.7591

[7] Narasimharaw, K.L., Pradeep, R., Mitra, S.K. and Pathak, I.C. (1983) Abdominal Tuberculosis Presenting as Inguinal Hernia. Indian Pediatrics, 20, 790-791.

[8] Lazarus, A. and Thilagar, B. (2007) Abdominal Tuberculosis. Disorders, 53, 32-38. https://doi.org/10.1016/j.disamonth.2006.10.004

[9] Basrur, G.B., Naik, R.P. and Nilesh, H. (2006) Primary Presentation of Abdominal Tuberculosis in an Inguinal Hernia. Indian Journal of Surgery, 68, 174-175. 